\title{
Towards a Systems Approach in the Genetic Analysis of Archaea: Accelerating Mutant Construction and Phenotypic Analysis in Haloferax volcanii
}

\author{
Ian K. Blaby, Gabriela Phillips, Crysten E. Blaby-Haas, Kevin S. Gulig, \\ Basma El Yacoubi, and Valérie de Crécy-Lagard \\ Department of Microbiology and Cell Science, University of Florida, Gainesville, FL 32611-0700, USA \\ Correspondence should be addressed to Valérie de Crécy-Lagard, vcrecy@ufl.edu
}

Received 2 September 2010; Accepted 24 October 2010

Academic Editor: Li Huang

Copyright ( $) 2010$ Ian K. Blaby et al. This is an open access article distributed under the Creative Commons Attribution License, which permits unrestricted use, distribution, and reproduction in any medium, provided the original work is properly cited.

\begin{abstract}
With the availability of a genome sequence and increasingly sophisticated genetic tools, Haloferax volcanii is becoming a model for both Archaea and halophiles. In order for $H$. volcanii to reach a status equivalent to Escherichia coli, Bacillus subtilis, or Saccharomyces cerevisiae, a gene knockout collection needs to be constructed in order to identify the archaeal essential gene set and enable systematic phenotype screens. A streamlined gene-deletion protocol adapted for potential automation was implemented and used to generate $22 \mathrm{H}$. volcanii deletion strains and identify several potentially essential genes. These gene deletion mutants, generated in this and previous studies, were then analyzed in a high-throughput fashion to measure growth rates in different media and temperature conditions. We conclude that these high-throughput methods are suitable for a rapid investigation of an $H$. volcanii mutant library and suggest that they should form the basis of a larger genome-wide experiment.
\end{abstract}

\section{Introduction}

Since the identification of the three-kingdom paradigm over 30 years ago [1], the quest for model archaeal organisms, representing each of the main groups, has been ongoing. To date, of the culturable Archaea, Sulfolobus sp. remain amongst the most intensely investigated and have become the subject of modern postgenomics experimental techniques $[2,3]$, yet in vivo studies in these organisms have lagged, as robust genetic methodologies are lacking (although this is now being addressed $[4,5]$ ). The ability of thermophiles, such as Thermococcus kodakaraensis and Pyroccocus furiosus, to thrive at in excess of $95^{\circ} \mathrm{C}$ is of great interest (particularly to industrials). However, whilst T. kodakaraensis has a welldeveloped genetic system, optimal growth at high temperatures coupled with anaerobic growth requirements puts these organisms out of reach of nonspecialist laboratories [6-8]. The methanogens received an early lead with the first available archaeal genome sequence, Methanococcus jannaschii [9], and genetic manipulation techniques have been described in the closely related Methanococcus maripaludis
$[10,11]$. Yet, as strict anaerobes, their manipulation is also still restricted to specialists.

Thanks to the endeavours of a growing community of investigators (see http://www.haloferax.org/), Haloferax volcanii is filling the role of model archeaon and model halophile. Its relatively short generation time of $<4$ hours [12, 13 , ease of growth under laboratory conditions, genomesequence availability [14], and development of genetic tools [15-17] (including shuttle, expression and suicide vectors using auxotrophy, and antibiotic-based selections) allow gene deletions to be achieved with relative ease. This combination of feats has enabled rapid progress in the study of halophiles and has been aided by the implementation of microarray and proteomics experiments in the closely related organism Halobacterium salinarum [18-21]. Hence, the $H$. salinarum/H. volcanii pair can be considered to be the most advanced model organisms in Archaea.

The construction of genome-wide gene deletion libraries have been one of the major achievements of the postgenomic era. Initially, such collections were generated using random mutagenesis approaches, and strain-sets using transposon 
insertions have been described for Escherichia coli [22], Corynebacterium glutamicum [23], Haemophilus influenza [24], and Pseudomonas aeruginosa [25, 26] among others. Yet, the potential polar effects of the insertion on downstream genes and the lack of certainty of gene-inactivation make transposon libraries far from ideal. For these reasons, targeted gene-deletion libraries have become the method of choice, despite higher cost and labor requirements. Such mutant collections have been constructed in multiple model organisms [27-29] and have greatly aided genefunction studies [30-32]. The genetic tools now available for halophiles, together with the logistical knowledge gained from previous genome-wide gene deletion libraries, is enabling a systematic analysis to be applied for the first time in an archaeal species. Systematic, and potentially automated, analysis of gene-deletion collections will enable rapid identification of strain phenotypes and should aid the annotation of hypothetical proteins.

As a proof-of-principle case study towards this goal, and to identify suitable approaches for the study of such a library, we analyzed 22 gene-deletion mutations generated in our laboratory using easily scalable high-throughput methods. Here, we report the statistics on the success of this endeavour and present the techniques used to establish accelerated genetics in H. volcanii. Furthermore, we employed highthroughput array-based phenotyping approaches, with the potential for scalability and automation, to aid the study of these and other mutants and demonstrate that $H$. volcanii is perfectly amenable to these techniques (assuming the predicted 4209 genes, the mutants analyzed here represent approximately $0.6 \%$ of all possible gene deletions). We propose the methods used here form the basis of a high-throughput phenotyping analysis of $H$. volcanii.

\section{Materials and Methods}

2.1. Strains, Plasmids, Media, and Transformation Procedures. All strains and plasmids used in this study are detailed in Supplementary Tables 1 and 2 available at doi:10.1155/2010/426239. H. volcanii $\mathrm{H} 26$ was used as the parent strain. E. coli was routinely grown in LB-Lennox (LB) (Fisher) or LB agar (Fisher) at $37^{\circ} \mathrm{C}$, supplemented when required with ampicillin (Amp; $100 \mu \mathrm{g} \mathrm{mL} \mathrm{m}^{-1}$ ), isopropyl $\beta$-D-1-thiogalactopyranoside (IPTG; $0.2 \mathrm{mM}$ ) and bromo-chloro-indolyl-galactopyranoside (X-gal; $40 \mu \mathrm{g} \mathrm{mL}^{-1}$ ). When required, novobiocin was added to a final concentration of $0.3 \mu \mathrm{g} \mathrm{mL} \mathrm{m}^{-1}$. H. volcanii cells were routinely grown at $44^{\circ} \mathrm{C}$ (unless specified) in $\mathrm{Hv}-\mathrm{YPC}$, $\mathrm{HvCA}$, or CDM. H. volcanii media was made according to the recipes provided in the HaloHandbook [12]. Transformations of chemically competent $E$. coli were performed as described by the manufacturer's directions (Invitrogen, CA). Transformation of $H$. volcanii was performed as described in the HaloHandbook using the "standard PEGmediated transformation of Haloarchaea" protocol. Briefly, spheroplasts were made by adding $100 \mu \mathrm{l} 0.5 \mathrm{M}$ EDTA (pH 8.0) to $1 \mathrm{~mL}$ concentrated cells and incubated at room temperature for $10 \mathrm{~min}$. $2 \mu \mathrm{g}$ of plasmid DNA were added to $100 \mu \mathrm{l}$ spheroplasts and incubated for $5 \mathrm{~min}$. $100 \mu \mathrm{l} 60 \%$ $(\mathrm{v} / \mathrm{v}) \mathrm{PEG}_{600}$ was added and mixed gently. The mixture was incubated at room temperature for $30 \mathrm{~min}$. Cells were recovered by adding recovery solution, as described in the HaloHandbook, and incubated for $4 \mathrm{hrs}$ at $44^{\circ} \mathrm{C}$ before plating onto the appropriate medium.

2.2. Gene Deletion Strain Construction. Plasmids to delete $H$. volcanii genes were constructed as follows. Regions of approximately $600 \mathrm{bp}$ upstream and downstream of the gene to be deleted were amplified by polymerase chain reaction (PCR) using Phusion Hot Start polymerase (Finnzymes, Espoo, Finland) from purified $H$. volcanii genomic DNA (prepared as described in [17]) with the primers listed in Supplemental Table 3. Primers were designed such that they contained 18-20 bases of homology to the chromosomal DNA. The reverse primer for the upstream fragment and the forward primer for the downstream fragment also contained a linker of 15 bases that enabled joining of the two fragments by recombination (described below). The linker was designed to incorporate a novel $15 \mathrm{bp}$ spacer between the up- and downstream fragments containing unique NdeI and MluI cut sites (Figure 1). The forward primer for the upstream fragment and the reverse primer for the downstream fragment also contained 15 bases of homology to the pTA131 (Figure 1). pTA131 was linearized by cutting with XhoI and EcoRI. After the two fragments and linearized vector were gel-purified (QiaQuick, Qiagen), they were combined in a 5:5:1 (upstream fragment:downstream fragment:linearized pTA131; see Figure 1) molar ratio (corrected to include $100 \mathrm{ng}$ linear vector) and recombined using In-Fusion as directed by the manufacturer (Clontech, CA). Reactions were incubated for $15 \mathrm{~min}$ at $37^{\circ} \mathrm{C}$ followed by $15 \mathrm{~min}$ at $50^{\circ} \mathrm{C}$. Subsequent to incubation, $0.2 \mu \mathrm{l}$ was transformed into Top10 cells (Invitrogen, CA) according to the manufacturer's directions and the cells plated onto LB plus Amp, IPTG, and X-gal. Clones were screened by PCR using M13 universal primers (which anneal either side of the MCS of pTA131) using $5^{\prime}$ Taq Master Mix (Eppendorf) as per the manufacturer's directions. Clones were verified by Sanger sequencing using the UF sequencing facility. The specific primers used to generate each gene-deletion construct are detailed in Supplemental Table 3.

Once obtained, the confirmed deletion plasmids were passaged through a dam ${ }^{-}$strain of Escherichia coli (Inv110; Invitrogen, CA), transformed into $H$. volcanii $\mathrm{H} 26$ (or derivatives) as described above. Deletion of the targeted locus was selected for in a two-step process as described previously by Allers et al. [16]. Briefly, recombination of the deletion plasmid into the chromosome by a single crossover event was selected for by growth on HvCA (i.e., in the absence of uracil). Subsequent excision of the integrated plasmid and target gene by a second recombination event was selected for by plating onto HvCA supplemented with uracil $\left(10 \mu \mathrm{g} \mathrm{mL}^{-1}\right)$ and 5-fluoroorotic acid (5-FOA; $50 \mu \mathrm{g}$ $\left.\mathrm{mL}^{-1}\right)$. Gene deletion candidates were screened using a PCR-based method as follows. The forward primer was designed to anneal $5^{\prime}$ to the downstream fragment, and 


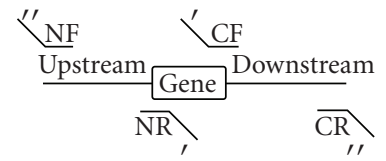

(a)

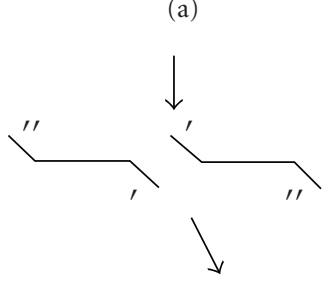

(b)

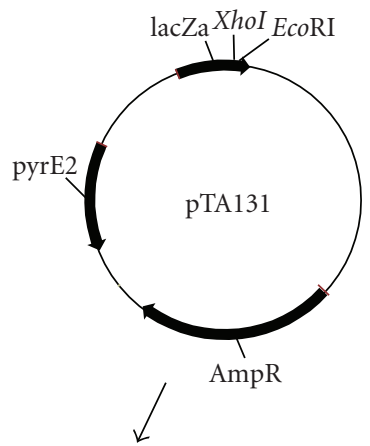

(c)

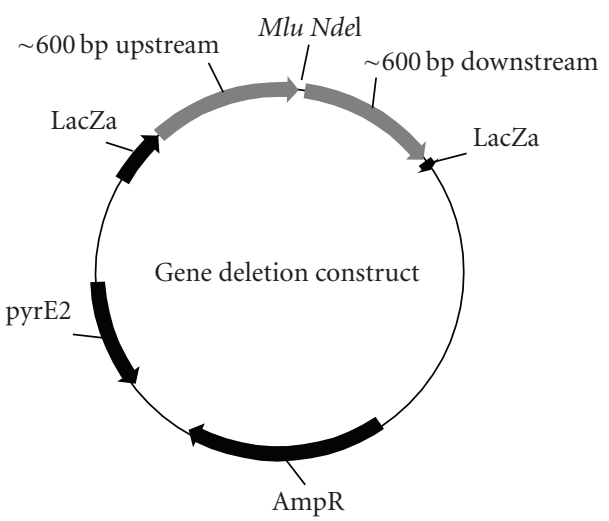

(d)

Figure 1: Generation of $H$. volcanii gene deletion constructs. Regions of approximately $600 \mathrm{bp}$ flanking the gene of interest were amplified from the $H$. volcanii chromosome (a) Regions of complementarity between primers are' and ". Complementarity sequences were $15 \mathrm{~b}$, as follows: NF: CGGGCCCCCCCTCGAG; NR: GACGCGTTCATATGC; CF: GCATATGAACGCGTC CR: CGGGCTGCAGGAATTC and were designed to yield unique MluI NdeI sites. Plasmid pTA131 was digested with EcoRI and XhoI (c) and the three fragments recombined using In-Fusion (d). Refer to Materials and Methods for details of the techniques used.

the reverse primer was designed to anneal within the upstream fragment. One pair of primers (denoted by the suffix _ext_Fwd and_ext_Rev) were designed to anneal within the flanking regions of the gene to be deleted and the amplicon size compared to wild-type and predicted sizes. To confirm loss of the gene, a second pair of primers (suffixed _int_Fwd and _int_Rev) was designed to anneal within the target gene to be deleted to confirm loss of the gene from the chromosome.

2.3. Other Plasmid Constructions. Target genes were amplified by PCR from purified $H$. volcanii genomic DNA using Phusion Hot Start polymerase (Finnzymes, Espoo, Finland), using primers listed in Supplementary Table 3. The amplicon was inserted between the NdeI and BlpI sites of pJAM202c [33].
2.4. H. volcanii tRNA Extraction and Analysis. Bulk tRNA was prepared, hydrolyzed, and analyzed by liquid chromatography-tandem mass spectrometry (LC-MS/MS) as described previously [34]. All tRNA purifications and analyses were performed independently at least twice.

2.5. High-Throughput Phenotype Analysis. For analysis of growth in liquid or on solid media, strains were routinely streaked from cryostorage onto Hv-YPC solid medium and incubated for $48 \mathrm{hrs}$ at $44^{\circ} \mathrm{C}$. Three tubes containing $5 \mathrm{~mL}$ of $\mathrm{Hv}$-YPC were inoculated independently with single colonies and grown at $44^{\circ} \mathrm{C}$ for $48 \mathrm{hrs}$.

For monitoring of $H$. volcanii growth curves, $2 \mu \mathrm{l}$ of culture normalized to an $\mathrm{OD}_{600}$ of 1 were used to inoculate either $300 \mu \mathrm{l}$ of Hv-YPC or $300 \mu \mathrm{l} \mathrm{CDM.} 250 \mu \mathrm{l}$ of inoculated medium was transferred to a 100-well plate. Growth curves were monitored in a Bioscreen-C Automated Growth Curve Analysis System (Growth Curves USA, MA) at $44^{\circ} \mathrm{C}$ with continuous shaking. Readings were recorded every $45 \mathrm{~min}$ (for clarity only one in 5 readings is shown in Figures 3(d) and $3(\mathrm{e})$ ). For the duration of the experiments conducted here, no special measures were necessary to prevent evaporation/salt precipitation from the Bioscreen plate.

For analysis of growth on solid media, wild-type and mutant strains were grown at a range of temperatures and salt concentrations. $100 \mu \mathrm{l}$ of each culture grown in Hv-YPC was normalized to an $\mathrm{OD}_{600}$ of 1 . This culture was serially diluted, and $10 \mu \mathrm{l}$ of the $10^{-4}$ dilution was plated onto a 96-well plate. Each well contained $100 \mu \mathrm{l}$ of Hv-YPC agar containing various salt concentrations. In addition to the standard final concentration of $18 \%$ salt water, as indicated in [12], the $30 \%$ salt water stock used to make standard Hv-YPC was diluted to achieve final concentrations of $12 \%$, $14 \%, 23 \%$ and $25 \%$. Each medium was duplicated so that the 6 salt concentrations occupied 12 wells (equating to a row on a 96-well plate). Each plate was replicated 5 times, and each incubated at $26^{\circ} \mathrm{C}, 30^{\circ} \mathrm{C}, 37^{\circ} \mathrm{C}, 44^{\circ} \mathrm{C}$ and $50^{\circ} \mathrm{C}$, thus yielding a matrix of temperature and salt concentration. Depending on the temperature, plates were incubated 2 to 7 days. The top row of each plate was used for a wild-type control, and the various mutants were added to subsequent rows.

\section{Results and Discussion}

3.1. Accelerating Gene Deletion Constructions in H. volcanii. The deletion of a large number of genes from the H. volcanii genome required the development of a fast method to obtain deletion constructs. Construction of $H$. volcanii gene deletions can be divided into two phases: (1) generation of the deletion construct which involves established E. colibased molecular biology, and (2) the introduction and selection of the correct gene-deletion candidate in the native organism. Phase 1 is hampered by the need to amplify by polymerase chain reaction (PCR) and clone multiple fragments of high GC content DNA (average 65\% [14]). Phase 2 is time consuming inherent to the technique and organism; two independent recombination events must be selected for in a relatively slow-growing organism. Currently, 


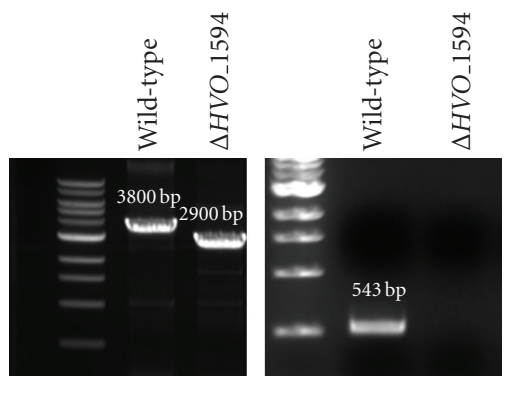

(a)

(d)
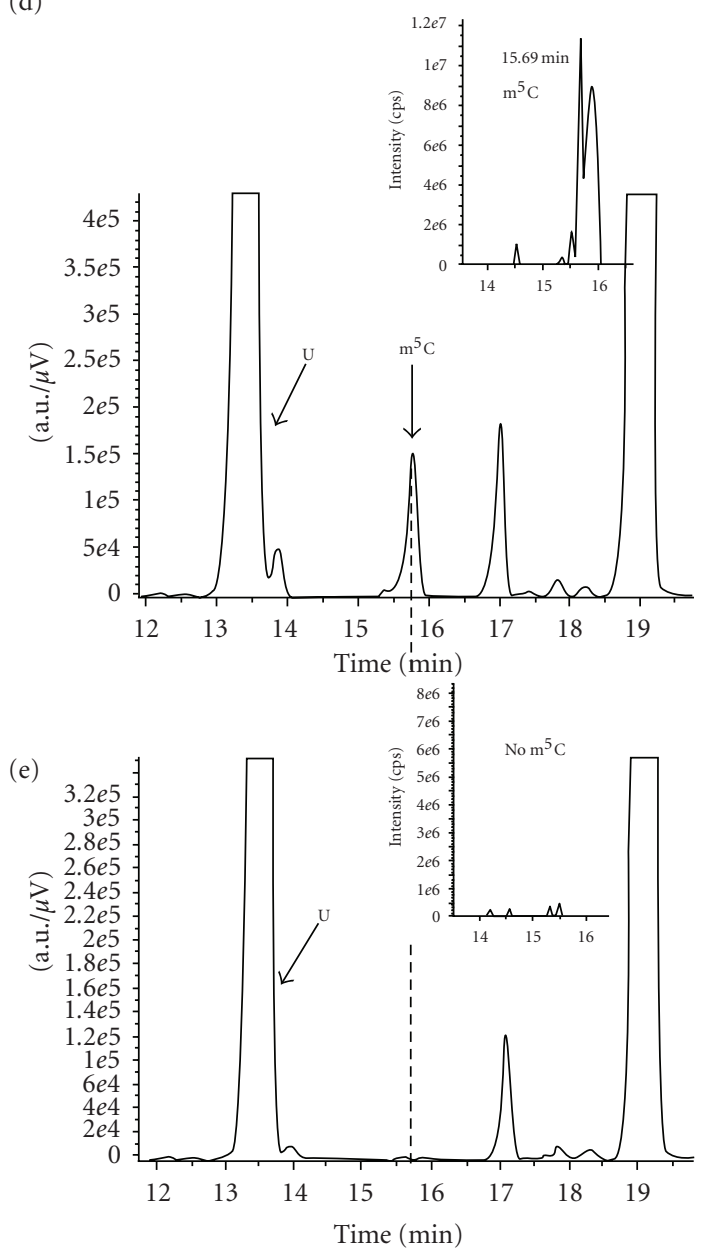

(d)

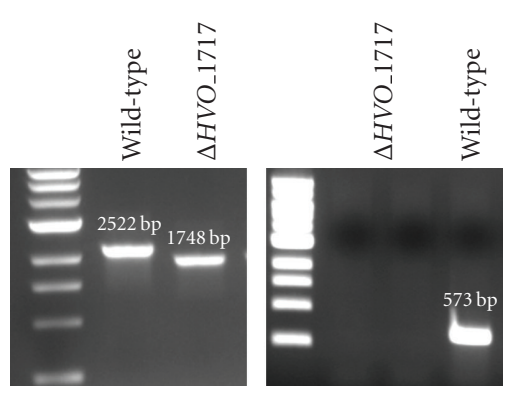

(b)

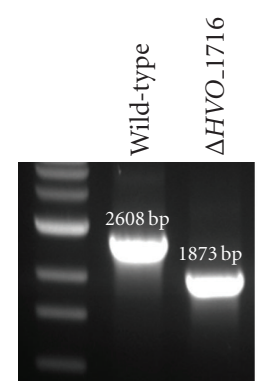

(c)

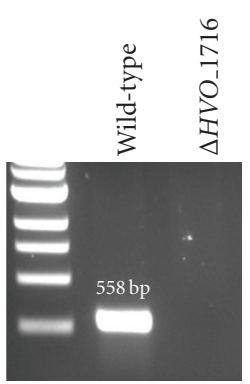

(f)
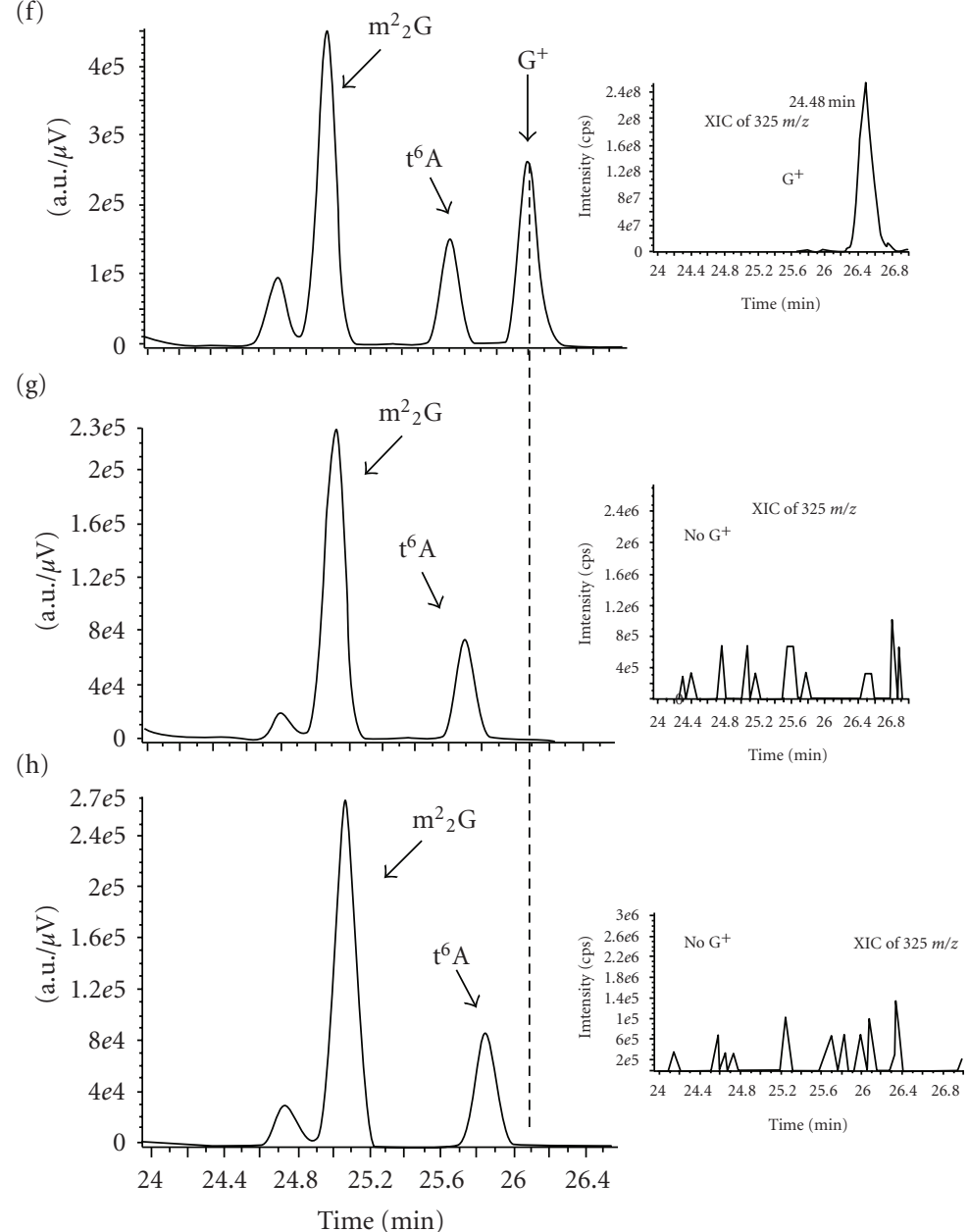

(e)

Figure 2: tRNA analysis. Gene deletions of (a) HVO_1594, (b) HVO_1717 and (c) HVO_1716 were verified by locus-specific PCR using primer pairs as indicated in Supplementary Table 3 designed to anneal outside and within the gene. Predicted amplicon sizes are indicated above each band. Analysis of LC-MS/MS tRNA extracted from $H$. volcanii strains showing the presence or absence of the $\mathrm{m}^{5} \mathrm{C}$ peak on the UV trace at $254 \mathrm{~nm}$ for H26 (d) and the corresponding extraction ion chromatogram for the H26 and $\triangle H V O \_1594$ (e). Fragmentation analyses of $\mathrm{m}^{5} \mathrm{C}$ are shown as insets. LC-MS/MS analyses of tRNA extracted from (f) H26, (g) $\Delta H V O \_1717$, and (h) $\Delta H V O \_1716$ indicate the presence and absence of $\mathrm{G}^{+}$. The peaks corresponding to $\mathrm{m}^{2}{ }_{2} \mathrm{G}$ and $\mathrm{t}^{6} \mathrm{~A}$ are shown for comparison. Fragmentation analyses of $\mathrm{G}^{+}$are shown as insets.

described methods require cloning the up- and downstream regions flanking the gene to be deleted either together (making the three-way ligation reaction between the two fragments and linearized vector relatively inefficient), sequential cloning (which is time consuming), or to use proprietary topoisomerase-based techniques which can be expensive when applied to large gene sets $[16,17]$. Thus, all existing techniques can require multiple rounds of cloning and as such are labor intensive and expensive, neither of which are desirable for the creation of large numbers 


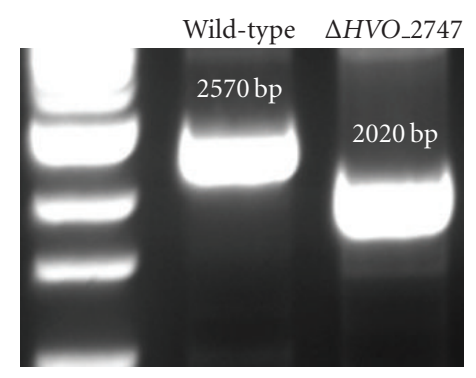

(a)

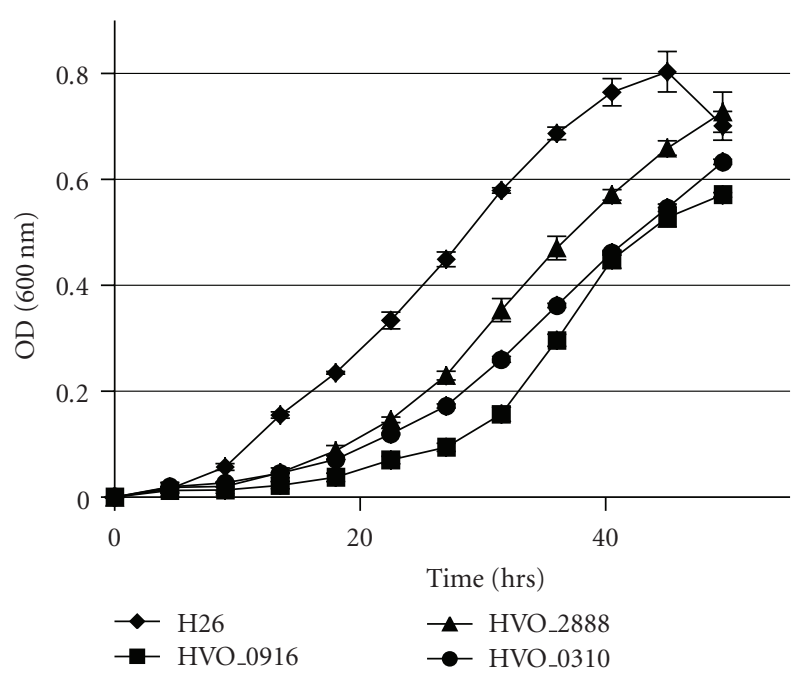

(d)

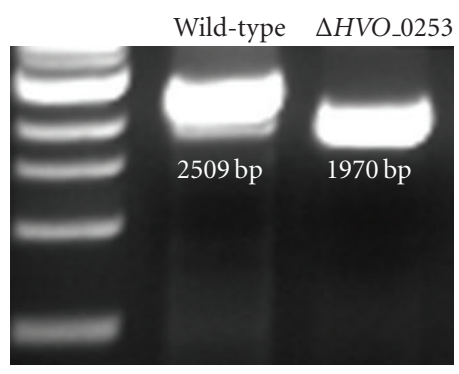

(b)

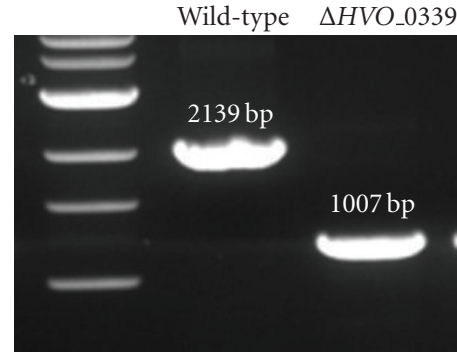

(c)

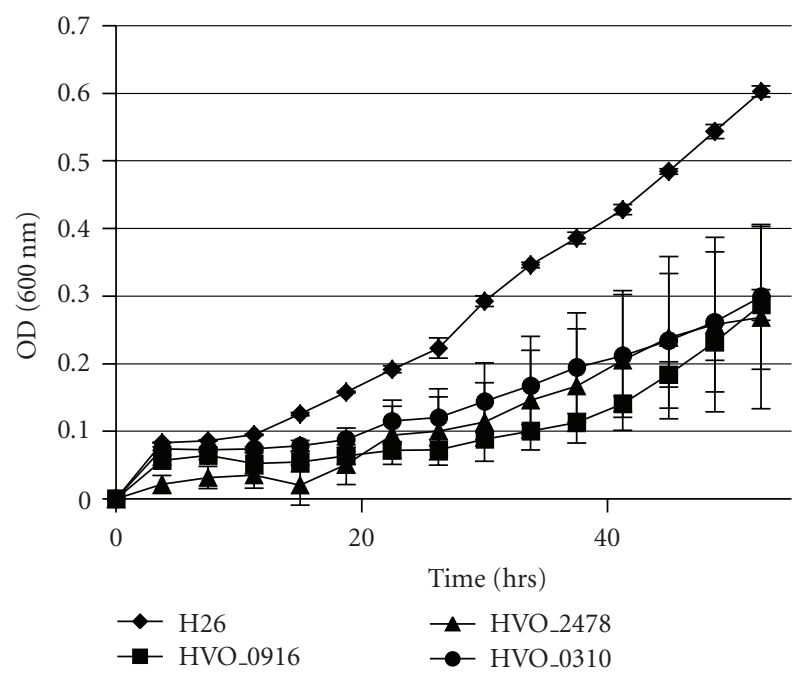

(e)

FIgURe 3: H. volcanii gene essentiality and growth analysis. Gene essentiality was confirmed by locus-specific PCR (a) HVO_2747, (b) HVO_0253, and (c) HVO_0339. Primers designed to anneal outside of the gene were used as detailed in Supplementary Table 3 and the amplicon size compared to the wild-type parent strain. Amplicon sizes are indicated beside each band. Growth analysis of $H$. volcanii $\mathrm{H} 26$ (wild-type) and the three most severe growth-defected strains in Hv-YPC media (d) and CDM (e). H26, HVO_0916, and HVO_0390 are indicated by diamonds, squares, and circles, respectively. Triangles indicate HVO_2888 (d) or HVO_2478 (e). Each point represents the mean of three independent biological repeats; error bars are plus and minus one standard error.

of gene deletions. To expedite the generation of mutants, we explored the possibility of recombineering deletion constructs rather than employing traditional established molecular biology techniques using In-Fusion (Clontech, CA; [35]). Detailed methodology of this technique are included in the Materials and Methods and shown schematically in Figure 1. Utilization of this system enabled deletion constructs to be synthesized within $24 \mathrm{hrs}$ of receiving the necessary oligonucleotides (compared to $2-4$ weeks using previously described methods) and verified gene deletions in $H$. volcanii were achieved in 3-4 weeks. Furthermore, due to the apparent high accuracy of the technique, fewer deletion-construct candidates needed to be screened prior to introduction to $H$. volcanii reducing time spent and cost (generally three candidate plasmids were screened using a PCR-based method, of which all three were almost always correct). Although around a month is still far beyond the time required for model organisms of other kingdoms, this period is unavoidable due to the relative slow growth of the organism and for the two recombination events implicit in the deletion protocol. However, adoption of this method enables the construction of large numbers of gene deletion constructs in a realistic timeframe. Furthermore, the same technique could in principle be applied to rapidly generate plasmid constructs to manipulate the genome by insertions, such as for in-frame chromosomal protein-fusion tags although this remains untested at present.

Traditionally, the $H$. volcanii community has preferred deletion verification by Southern hybridization methods. Here, with the large number of putative mutants to screen, we have adopted the 2-fold PCR-based mutant verification process employed in $H$. volcanii by El Yacoubi et al. [17]. In addition to being at least as sensitive as Southern hybridizations, PCR is easily scalable. Two primers are designed to anneal outside of the affected gene, and two within. The two PCR reactions performed with these primers confirm alteration of the genomic region and are validated by comparison with the predicted amplicon size, and the primers landing within the gene absolutely confirm its absence when compared to the wild-type parent strain positive control. Generally, 36 candidates were screened 
which, in the cases mutants were achieved, typically yielded several deletions. The theoretical 50\% mutant generation from resolution of the merodiploid was rarely achieved, possibly due to recombination restraints resulting from localized secondary structure. If gene deletions could not be identified, a further 100 candidates were screened, and if no mutants still were exhibited, the entire process was repeated at least once.

Using this protocol, 21 genes were successfully deleted out of 30 attempted (Table 1 ), and one strain was constructed containing two gene deletions (AHVO_1105 $\left.\triangle H V O \_2008\right)$. To demonstrate the validity of our protocol, we further analyzed phenotypes of specific mutants. HVO_1594 was previously predicted to be responsible for the formation of the tRNA modification $\mathrm{m}^{5} \mathrm{C}$ on the basis of homology with $P$. abyssi protein PAB1947 [36], a modification shown to be present in almost all $H$. volcanii tRNA species [37]. HVO_1594 was deleted from the chromosome using the method described above, and bulk tRNA from wild type and $\triangle H V O \_1594$ cells grown in Hv-YPC media were analyzed by LC-MS/MS (Figure 2). As shown in Figure 2, the peak corresponding to $\mathrm{m}^{5} \mathrm{C}$ was absent from the tRNA extracted from the mutant. The identity of the corresponding peak from wild-type tRNA was confirmed by tandem mass fragmentation. Thus the LC-MS/MS analysis was consistent with the involvement of $\mathrm{HVO}_{-} 1594$ in the formation of $\mathrm{m}^{5} \mathrm{C}$ in tRNA.

HVO_1717 and HVO_1716 are the respective homologs of bacterial queE and queC involved in the synthesis of preQ $_{0}$, a precursor of the Queuosine modification found in bacterial tRNA $[38,39]$. preQ $_{0}$ is also a precursor in the biosynthesis of Archaeosine $\left(\mathrm{G}^{+}\right)$[40], a tRNA modification of the D-loop found in almost all archaeal tRNA species sequenced to date [41]. As these two modifications share the same precursor, a likely hypothesis is that HVO_1717 and HVO_1716 are involved in $\mathrm{G}^{+}$biosynthesis. To test this, the corresponding gene deletion mutants were constructed as described in the Materials and Methods and, to avoid potential contamination of $\mathrm{preQ}_{0}$ from rich media [40], grown in defined media (CDM). The bulk tRNA extracted from these mutant strains, was purified and digested to ribonucleosides (Figure 2). Analysis by LC-MS/MS demonstrated that the peak corresponding to the $\mathrm{G}^{+}$was absent in both of the mutant strains but present in the wild-type. Identity of the peak from the wild-type sample was confirmed by tandem mass fragmentation (Figure 2). These results confirmed that HVO_1717 (queE) and HVO_1716 (queC) are involved in $\mathrm{G}^{+}$biosynthesis.

3.2. Discovering Essential Genes in $H$. volcanii. Using our techniques, we set out to delete 30 genes (Table 1). 22 strains were successfully constructed (Table 1); however, despite multiple attempts, eight genes could not be deleted (Table 1) raising the possibility that they were essential. To determine whether these were bona fide essential genes, and thus form the basis of the $H$. volcanii essential gene set alongside the likes of cct1, hdaI, and pitA [42-44], each of the eight genes were cloned into an E. coli/H. volcanii shuttle vector pJAM202. The clones were transformed into $H$. volcanii $\mathrm{H} 26$ derivatives whose chromosomes carried a verified integration of the corresponding gene deletion construct (see Section 2). With the specific genes expressed to high levels in trans, attempts were made again to delete the corresponding chromosomal gene copy. Deletion of the gene in this situation was checked as described in Materials and Methods, except that internal primers were not used as they would amplify a product regardless of successful deletion. Using this methodology, we successfully achieved deletion of the chromosomal copies of HVO_0339, HVO_0253, and HVO_2747 suggesting that these genes are genuinely essential (Figures 3(a)-3(c)). Testing of the remaining five essential gene candidates is ongoing.

The essentiality of two of these three genes is expected. HVO_0339, a member of the COG1517 family, was recently shown in vitro to be responsible for the modification of cytidine to agmatidine at the wobble position of tRNA ${ }^{\text {Ile- }} \mathrm{CAU}$ $[45,46]$. Agmatidine allows the modified tRNA ${ }^{\text {Ile- }} \mathrm{CAU}$ to decode AUA isoleucine codons and not methionine AUG codons $[45,46]$. The functionally analogous modification in bacteria, lysidine, is essential [47]. HVO_0253 is a member of the YrdC/Sua5 family involved in the formation of $\mathrm{N}^{6}$ threonylcarbamoyl adenosine $\left(\mathrm{t}^{6} \mathrm{~A}\right)$, a universal modification found at position 37 of tRNAs decoding ANN codons [48]. The corresponding gene family is essential in bacteria, and deletion of the yeast homologue (YGL169W) is viable but leads to severe growth phenotypes [48]. The essentiality of $\mathrm{HVO}_{0} 0253$ reveals that concerning the role of $\mathrm{t}^{6} \mathrm{~A}$ biosynthesis enzymes, Archaea are closer to bacteria than to eukaryotes. Finally, the function of HVO_2747, a member of COG1491, remains unknown, but its conservation in most Archaea, combined with the essentiality phenotype, makes it a top target for study. Our genetic results strongly suggest the three genes described above are essential but future investigation utilizing the previously described $\mathrm{P}_{T N A}$ promoter [44] will confirm this essentiality phenotype as well as determine the level of expression required for viability.

3.3. High-Throughput Growth Rate Analysis of H. volcanii Mutants. Having deleted a relatively large number of genes, a second major goal of this study was to develop and implement high-throughput phenotyping and physiology approaches to an $H$. volcanii. Whilst these approaches have been applied to the analysis of $H$. salinarum [49], similar methods have not been performed with $H$. volcanii. Array-based phenotyping approaches (used to derive the "phenome") have been employed in other model organisms to great success ( [50-52] and recently reviewed in [53]). Should a $H$. volcanii gene deletion library be constructed in the future, similar methods will be necessary for the functional assessment of a large number of mutants. We, therefore, initiated an investigation in which growth studies of wild-type and all mutant strains constructed in our laboratory in the last few years were compared in a range of conditions and media types. Our methods were designed to generate a large, quantitative dataset whilst maintaining 
TABLE 1: Gene-deletion summary.

\begin{tabular}{|c|c|c|c|c|}
\hline Gene & COG & Strain growth rate Hv-YPC & Strain growth rate $\mathrm{CDM}^{\mathrm{a}, \mathrm{b}}$ & Phenotype/essentiality verified \\
\hline H26 (wild-type) & - & 0.0227 & 0.0133 & - \\
\hline HVO_0156 & 1041 & 0.0223 & 0.0105 & \\
\hline HVO_0658 & 0585 & 0.0281 & 0.0175 & \\
\hline HVO_2001 & 0343 & 0.0233 & 0.0123 & Cold-sensitivity \\
\hline HVO_0236 & 1867 & 0.0238 & 0.0104 & \\
\hline HVO_2906 & 0565 & $\mathrm{ND}^{\mathrm{c}}$ & $\mathrm{ND}^{\mathrm{c}}$ & \\
\hline HVO_2888 & 1243 & 0.0102 & 0.0115 & Severe growth defect \\
\hline HVO_0580 & 0037 & 0.0271 & 0.0124 & \\
\hline HVO_2736 & 1444 & 0.0210 & 0.0115 & $(20)$ \\
\hline HVO_1852 & 0101 & 0.0151 & 0.0151 & Growth defect \\
\hline HVO_1594 & 0144 & 0.0107 & 0.0107 & Growth defect \\
\hline HVO_0916 & 1798 & 0.0055 & 0.0088 & Cold-sensitivity, severe growth defect \\
\hline HVO_1631 & 4112 & 0.0196 & 0.0097 & Cold-sensitivity, slight growth defect \\
\hline HVO_2477 & 2890 & 0.0219 & 0.0117 & Cold-resistance \\
\hline HVO_1716 & 0603 & 0.022 & 0.0143 & \\
\hline HVO_1717 & 0602 & 0.020 & 0.0118 & \\
\hline HVO_B0354 & 1357 & 0.0266 & 0.0128 & \\
\hline HVO_0390 & 2016 & 0.0066 & 0.0064 & Severe growth defect \\
\hline HVO_2478 & 0042 & 0.0243 & 0.0075 & Defined media growth defect \\
\hline HVO_1475 & 2263 & 0.0266 & 0.0177 & \\
\hline HVO_1105 & 1374 & 0.0216 & 0.0124 & \\
\hline HVO_2008 & 1549 & 0.0245 & 0.0154 & \\
\hline HVO_1105 & 1374, & 0.025 & 0.0127 & \\
\hline HVO_0574 & 2226 & \multicolumn{2}{|c|}{ Not deleted } & Predicted essential \\
\hline HVO_0339 & 1571 & \multicolumn{2}{|c|}{ Not deleted } & Deleted only when gene present in trans \\
\hline HVO_0697 & 2047 & \multicolumn{2}{|c|}{ Not deleted } & Predicted essential \\
\hline HVO_0253 & 0009 & \multicolumn{2}{|c|}{ Not deleted } & Deleted only when gene present in trans \\
\hline HVO_1173 & 1303 & \multicolumn{2}{|c|}{ Not deleted } & Predicted essential \\
\hline HVO_1383 & 2519 & \multicolumn{2}{|c|}{ Not deleted } & Predicted essential \\
\hline HVO_2747 & 1491 & \multicolumn{2}{|c|}{ Not deleted } & Deleted only when gene present in trans \\
\hline HVO_0929 & & \multicolumn{2}{|c|}{ Not deleted } & Predicted essential \\
\hline
\end{tabular}

growth rates are presented $\mathrm{hr}^{-1}$

$\mathrm{b}_{0.4 \%}(\mathrm{v} / \mathrm{v})$ glycerol used as a carbon source.

${ }^{\mathrm{c}}$ Not determined.

a manageable, and easily scalable, labour load. We explored two approaches to strain phenotyping. The first approach was to perform growth curves in a 100-well format, and the second was determination of fitness of strains grown on solid media in a 96-well format. For growth curves, wildtype and 21 mutant strains were grown in rich (Hv-YPC) and defined media (CDM). Secondly, for solid media, those same strains were grown at a range of temperatures and salt concentrations. Each experiment contained at least two independent biological replicates. Using these techniques, we identified multiple novel phenotypes with one researcher in 2 weeks (summarized in Table 1, Figures 3 and 4 and Supplementary Table 4).

A Bioscreen C apparatus was employed to obtain growth parameters of all strains in rich medium (Hv-YPC) and defined medium $(\mathrm{CDM})$ to determine whether any gene deletions under investigation here were detrimental to growth. Many of the strains maintained growth rates that were indistinguishable from the wild type, however 7 mutants exhibited severe growth defects (Table 1 and Figures 3(d) and 3(e)). As would be expected, more mutants exhibited phenotypes when grown in defined (CDM) medium (Table 1). $\Delta H V O \_0390, \Delta H V O \_0916$, and $\triangle H V O \_2888$ displayed the most severe growth defects in rich medium (Figures 3(d) and 3(e)). $\triangle H V O \_0916, \Delta H V O \_0390$, and $\triangle H V O 2478$ displayed the three most severe growth defects in defined medium (Figure 3). Complete growthrate calculations of all strains in both media types are summarized in Table 1. Although the growth rate constants corresponding to doubling times of $\sim 20 \mathrm{hrs}$ are lower than has previously been reported $[12,13]$, this appears an artefact of using the Bioscreen $\mathrm{C}$ apparatus, where culture 


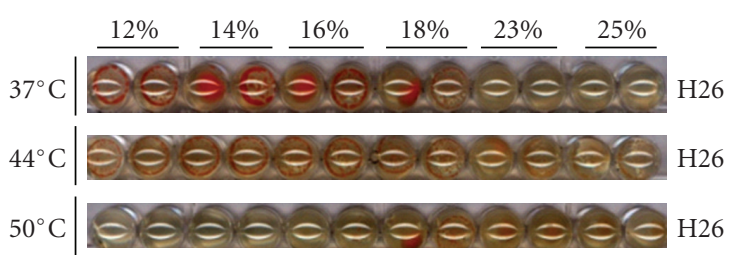

(a)
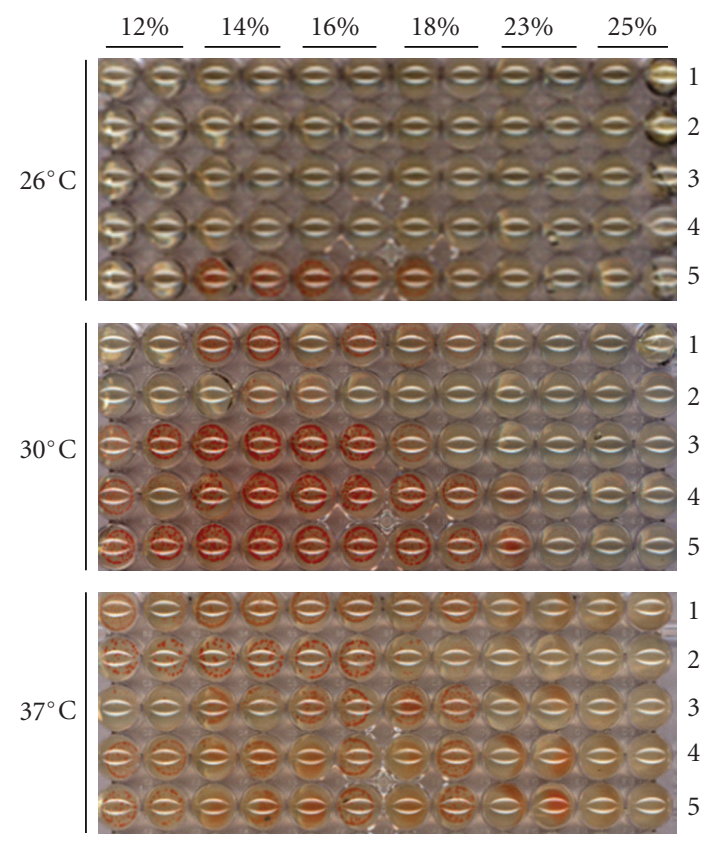

$1 \mathrm{H} 26$

$2 \triangle H V O \_0916$

$3 \triangle H V O \_1631$

$4 \Delta$ HVO_2001

$5 \triangle H V O \_2477$

(b)

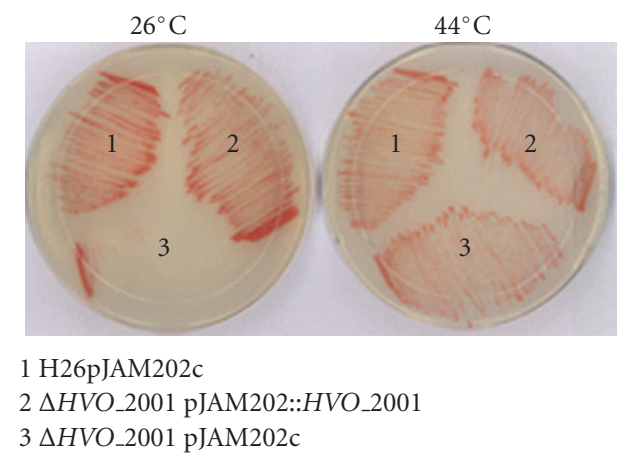

(c)

FIGURE 4: Salt and temperature tolerance of $H$. volcanii strains. ((a) and (b)) H26 (wild-type) and mutant strains (b) were subjected to high and low temperature and salt concentration. The salt concentration and temperature are indicated above each well. (c) H26 (1), $\Delta H V O \_2001$ (2), and complemented $\Delta H V O \_2001$ (3) streaked onto $\mathrm{Hv}-\mathrm{YPC}$ and incubated at $26^{\circ} \mathrm{C}$ or $44^{\circ} \mathrm{C}$ as indicated. agitation, and therefore aeration, are significantly lower than in large cultures in a regular shaking incubator. As a control for this, H26 was grown in the same Hv-YPC media in regular culture flasks and determined to have a doubling time of $\sim 4.5 \mathrm{hrs}$, strongly suggesting the differences are solely a result of the 100-well format used. HVO_0390 is a member of COG2016. The yeast homolog, Tma20, was identified as a ribosome-associated protein [54]. Loss of Tma20 caused a significant increase in ochre and opal codon read through in yeast [54]. The corresponding gene physically clusters with ribosomal protein genes in many archaeal genomes ([55] and see Tma20 subsystem on the SEED database http://theseed.uchicago.edu/FIG/SubsysEditor.cgi?page $=$ ShowSpreadsheet\&subsystem=DOE_COG2016). Therefore, although it remains untested at present, a role for HVO_0390 in maintaining translation fidelity in Archaea appears probable, and given this, the reduced growth rate of the corresponding deletion mutant is not surprising. HVO_0916 is homologous to Diphtine Synthase (Dph5), a methyltransferase of the diphtamide biosynthetic pathway. Diphtamide is a post translational modification found in Elongation factor 2 (EF2) in Archaea and eukaryotes and is the target of the diphtheria toxin [56-58]. Although the precise function of this modification remains unknown, deletion of genes in this pathway results in growth phenotypes and translation defects in yeast [59] and severely impaired development in mammals [60,61]. Our analysis suggests that growth defects due to absence of diphtamide are also observed in Archaea, but this remains to be validated by confirming the absence of the modification in EF2 due to deletion of HVO_0916. These results suggest that obtaining growth curve analyses in a high-throughput fashion is a viable approach to study $H$. volcanii gene function and physiology.

3.4. High Throughput Phenotyping of H. volcanii Mutants. A key question in the analysis of halophiles, and Archaea at large, is to understand their ability to thrive in seemingly inhospitable environments. To begin to address this, and with the long-term intention of identifying the underlying genetic and molecular basis for this ability, the parent strain and mutants were subjected to growth at a range of temperatures $\left(26^{\circ} \mathrm{C}-50^{\circ} \mathrm{C}\right)$ and salt concentrations $(12 \%-25 \%)$. An interesting observation that was revealed by comparing large numbers of plates simultaneously is that $H$. volcanii salt tolerance appears to be dependent on temperature. At relatively low temperatures $\left(26^{\circ} \mathrm{C}-\right.$ $37^{\circ} \mathrm{C}$ ), there is a clear preference for relatively high salt concentrations whereas at higher temperature $\left(50^{\circ} \mathrm{C}\right)$, salt tolerance decreases, and high salt concentration becomes inhibitive to growth (Figure 4(a)). Comparison of growth of wild-type to mutant strains across the various salt concentrations and temperatures revealed several strains that exhibit cold sensitivities. These included deletions in HVO_0916, HVO_1631, and HVO_2001 (Figure 4(b) and Supplementary Table 4). Conversely, the strain bearing a deletion in HVO_2477 exhibits increased tolerance to low temperature. 
As often seen when deleting components of the translation apparatus [62, 63], deleting HVO_0916, HVO_1631, and HVO_2001 gave rise to cold sensitivity phenotypes. As discussed above, HVO_0916 is homologous to the diphthamide biosynthesis protein Dph5 and HVO_1631 is homologous to Dph2, the first enzyme of the pathway [64]. HVO_2001 encodes a tRNA-guanine-transglycosylase (TGT) [17]. TGT is a key enzyme in the synthesis of Archaeosine $\left(\mathrm{G}^{+}\right)$, a modification of tRNA found specifically in Archaea. $\mathrm{G}^{+}$is found at the elbow of the D-arm and T-arm at position 15 of almost all archaeal tRNA bearing a guanine at this position. We had previously shown that $\triangle H V O \_2001$ was viable and lacked $\mathrm{G}^{+}$in tRNA [17]. The results here show a first growth phenotype for an Archaeon lacking Archaeosine, cold sensitivity. In eukaryotic and bacterial tRNA, position 15 is part of the $\mathrm{Mg}^{2+}$ binding site $[65,66] . \mathrm{Mg}^{2+}$ ions induce folding and maintain the tRNA tertiary structure $(16,43,48$, and 52). Also, Oliva et al. showed that in silico, $\mathrm{Mg}^{2+}$ and $\mathrm{G}^{+}$play an interchangeable role in stabilizing the G15-C48 Reverse Watson-Crick geometry [67]. Together, these studies imply that $\mathrm{G}^{+}$might play a role in inducing folding and maintaining the structural integrity of tRNA. Therefore, the absence of the $\mathrm{G}^{+}$modification could confer more rigidity to tRNA and perturb folding at low temperatures explaining the coldsensitivity phenotype. To independently confirm the 96well plate assays, we reproduced the $\triangle H V O \_2001$ phenotype on $100 \mathrm{~mm}$ petri dishes (Figure 4(c)) and complemented the cold-sensitivity phenotype by expressing the HVO_2001 in trans. As HVO_2001, HVO_1717, and HVO_1716 form part of the same pathway for $\mathrm{G}^{+}$biosynthesis, the same cold-sensitivity phenotype might also be expected in strains bearing deletions of $H V O \_1717$ and $H V O \_1716$. However, we did not observe a cold-sensitivity phenotype for these two genes. An explanation for this observation is the possibility of preQ $_{0}$ salvage from rich media (on which these phenotype screens were performed). Therefore, in these strains $\mathrm{G}^{+}$is still made. This hypothesis could be tested by repeating these assays on defined medium, where salvage of the $\mathrm{PreQ}_{0}$ base would not occur.

In conclusion, we have employed modern recombineering-based methods to rapidly generate gene-deletion constructs, ultimately resulting in the construction of 22 strains. Eight genes included in our pipeline could not be deleted by these methods; we genetically demonstrated provided evidence for the probable essentiality of 3 of those. Furthermore, using array-based phenotyping methods, we were able to identify multiple growth phenotypes of the mutants analyzed using methods that could easily be scaled to encompass much larger gene-deletion collections. The work presented here paves a potential road for the systematic creation and analysis of a global $H$. volcanii gene-deletion library, which would support the genetic analysis of the plethora of hypothetical and poorly annotated genes in Archaea.

\section{Authors' Contributions}

IKB and VdC-L designed \& performed research and wrote the manuscript. GP, CEB, KG and BEY helped with strain construction. GP, CEB and BEY helped with the design of the phenotypic analysis.

\section{Acknowledgments}

This work was funded by National Science Foundation Grant no. MCB-05169448 to V. de Crécy-Lagard H. volcanii, H26, and pJAM202c were gifts from J. Maupin-Furlow. LCMS/MS experiments were performed by Sophie Alvarez, and the authors thank Henri Grosjean for constant suggestions and support.

\section{References}

[1] C. R. Woese and G. E. Fox, "Phylogenetic structure of the prokaryotic domain: the primary kingdoms," Proceedings of the National Academy of Sciences of the United States of America, vol. 74, no. 11, pp. 5088-5090, 1977.

[2] S.-V. Albers, N.-K. Birkeland, A. J. M. Driessen et al., "SulfoSYS (Sulfolobus Systems Biology): towards a silicon cell model for the central carbohydrate metabolism of the archaeon Sulfolobus solfataricus under temperature variation," Biochemical Society Transactions, vol. 37, no. 1, pp. 58-64, 2009.

[3] T. K. Pham, P. Sierocinski, J. Van Der Oost, and P. C. Wright, "Quantitative proteomic analysis of Sulfolobus solfataricus membrane proteins," Journal of Proteome Research, vol. 9, no. 2, pp. 1165-1172, 2010.

[4] S. Berkner and G. Lipps, "Genetic tools for Sulfolobus spp.: vectors and first applications," Archives of Microbiology, vol. 190, no. 3, pp. 217-230, 2008.

[5] M. Wagner, S. Berkner, M. Ajon, A. J. M. Driessen, G. Lipps, and S.-V. Albers, "Expanding and understanding the genetic toolbox of the hyperthermophilic genus Sulfolobus," Biochemical Society Transactions, vol. 37, no. 1, pp. 97-101, 2009.

[6] T. Sato, T. Fukui, H. Atomi, and T. Imanaka, "Improved and versatile transformation system allowing multiple genetic manipulations of the hyperthermophilic archaeon Thermococcus kodakaraensis," Applied and Environmental Microbiology, vol. 71, no. 7, pp. 3889-3899, 2005.

[7] T. Sato, T. Fukui, H. Atomi, and T. Imanaka, "Targeted gene disruption by homologous recombination in the hyperthermophilic archaeon Thermococcus kodakaraensis KOD1," Journal of Bacteriology, vol. 185, no. 1, pp. 210-220, 2003.

[8] I. Waege, G. Schmid, S. Thumann, M. Thomm, and W. Hausner, "Shuttle vector-based transformation system for pyrococcus furiosus," Applied and Environmental Microbiology, vol. 76, no. 10, pp. 3308-3313, 2010.

[9] C. J. Bult, O. White, G. J. Olsen et al., "Complete genome sequence of the Methanogenic archaeon, Methanococcus jannaschii," Science, vol. 273, no. 5278, pp. 1058-1073, 1996.

[10] B. C. Moore and J. A. Leigh, "Markerless mutagenesis in Methanococcus maripaludis demonstrates roles for alanine dehydrogenase, alanine racemase, and alanine permease," Journal of Bacteriology, vol. 187, no. 3, pp. 972-979, 2005.

[11] M. A. Pritchett, J. K. Zhang, and W. W. Metcalf, "Development of a markerless genetic exchange method for Methanosarcina acetivorans $\mathrm{C} 2 \mathrm{~A}$ and its use in construction of new genetic tools for methanogenic archaea," Applied and Environmental Microbiology, vol. 70, no. 3, pp. 1425-1433, 2004. 
[12] M. Dyall-Smith, The Halohandbook: Protocols for Halobacterial Genetics, vol. 6.01, 2006, http://www.microbiol.unimelb.edu .au/micro/staff/mds/HaloHandbook/.

[13] A. Zaigler, S. C. Schuster, and J. Soppa, "Construction and usage of a onefold-coverage shotgun dna microarray to characterize the metabolism of the archaeon Haloferax volcanii," Molecular Microbiology, vol. 48, no. 4, pp. 1089-1105, 2003.

[14] A. Hartman, C. Norais, J. Badger et al., "The complete genome sequence of Haloferax volcanii DS2, a model archaeon," PLoS One, vol. 5, article no. e9605, 2010.

[15] T. Allers, S. Barak, S. Liddell, K. Wardell, and M. Mevarech, "Improved strains and plasmid vectors for conditional overexpression of His-tagged proteins in Haloferax volcanii," Applied and Environmental Microbiology, vol. 76, no. 6, pp. 1759-1769, 2010.

[16] T. Allers, H.-P. Ngo, M. Mevarech, and R. G. Lloyd, "Development of additional selectable markers for the halophilic archaeon Haloferax volcanii based on the leuB and trpA genes," Applied and Environmental Microbiology, vol. 70, no. 2, pp. 943-953, 2004.

[17] B. El Yacoubi, G. Phillips, I. K. Blaby et al., "A gateway platform for functional genomics in Haloferax volcanii: deletion of three tRNA modification genes," Archaea, vol. 2, no. 4, pp. 211-219, 2009.

[18] B. Bisle, A. Schmidt, B. Scheibe et al., "Quantitative profiling of the membrane proteome in Halophilic archaeon," Molecular and Cellular Proteomics, vol. 5, no. 9, pp. 1543-1558, 2006.

[19] C. Lange, A. Zaigler, M. Hammelmann et al., "Genome-wide analysis of growth phase-dependent translational and transcriptional regulation in halophilic archaea," BMC Genomics, vol. 8, article no. 415, 2007.

[20] A. Tebbe, A. Schmidt, K. Konstantinidis et al., "Life-style changes of a halophilic archaeon analyzed by quantitative proteomics," Proteomics, vol. 9, no. 15, pp. 3843-3855, 2009.

[21] J. Twellmeyer, A. Wende, J. Wolfertz et al., "Microarray analysis in the archaeon Halobacterium salinarum strain R1," PLoS ONE, vol. 2, no. 10, article no. e1064, 2007.

[22] S. Y. Gerdes, M. D. Scholle, J. W. Campbell et al., "Experimental determination and system level analysis of essential genes in Escherichia coli MG1655," Journal of Bacteriology, vol. 185, no. 19 , pp. 5673-5684, 2003.

[23] N. Suzuki, N. Okai, H. Nonaka, Y. Tsuge, M. Inui, and H. Yukawa, "High-throughput transposon mutagenesis of Corynebacterium glutamicum and construction of a singlegene disruptant mutant library," Applied and Environmental Microbiology, vol. 72, no. 5, pp. 3750-3755, 2006.

[24] B. J. Akerley, E. J. Rubin, V. L. Novick, K. Amaya, N. Judson, and J. J. Mekalanos, "A genome-scale analysis for identification of genes required for growth or survival of Haemophilus influenzae," Proceedings of the National Academy of Sciences of the United States of America, vol. 99, no. 2, pp. 966-971, 2002.

[25] M. A. Jacobs, A. Alwood, I. Thaipisuttikul et al., "Comprehensive transposon mutant library of Pseudomonas aeruginosa," Proceedings of the National Academy of Sciences of the United States of America, vol. 100, no. 2, pp. 14339-14344, 2003.

[26] N. T. Liberati, J. M. Urbach, S. Miyata et al., "An ordered, nonredundant library of Pseudomonas aeruginosa strain PA14 transposon insertion mutants," Proceedings of the National Academy of Sciences of the United States of America, vol. 103, no. 8, pp. 2833-2838, 2006.

[27] T. Baba, T. Ara, M. Hasegawa et al., "Construction of Escherichia coli K-12 in-frame, single-gene knockout mutants: the Keio collection," Molecular Systems Biology, vol. 2, article no. $2006.0008,2006$.
[28] G. Giaever, A. M. Chu, L. Ni et al., "Functional profiling of the Saccharomyces cerevisiae genome," Nature, vol. 418, no. 6896, pp. 387-391, 2002.

[29] K. Kobayashi, S. D. Ehrlich, A. Albertini et al., "Essential Bacillus subtilis genes," Proceedings of the National Academy of Sciences of the United States of America, vol. 100, no. 8, pp. 4678-4683, 2003.

[30] M. E. Hillenmeyer, E. Ericson, R. W. Davis, C. Nislow, D. Koller, and G. Giaever, "Systematic analysis of genome-wide fitness data in yeast reveals novel gene function and drug action," Genome Biology, vol. 11, no. 3, article no. r30, 2010.

[31] M. E. Hillenmeyer, E. Fung, J. Wildenhain et al., "The chemical genomic portrait of yeast: uncovering a phenotype for all genes," Science, vol. 320, no. 5874, pp. 362-365, 2008.

[32] C. Tamae, A. Liu, K. Kim et al., "Determination of antibiotic hypersensitivity among 4,000 single-gene-knockout mutants of Escherichia coli," Journal of Bacteriology, vol. 190, no. 17, pp. 5981-5988, 2008.

[33] S. J. Kaczowka and J. A. Maupin-Furlow, "Subunit topology of two 20S proteasomes from Haloferax volcanii," Journal of Bacteriology, vol. 185, no. 1, pp. 165-174, 2003.

[34] V. de Crécy-Lagard, C. Brochier-Armanet, J. Urbonaviius et al., "Biosynthesis of wyosine derivatives in tRNA: an ancient and highly diverse pathway in archaea," Molecular Biology and Evolution, vol. 27, no. 9, pp. 2062-2077, 2010.

[35] B. Zhu, G. Cai, E. O. Hall, and G. J. Freeman, "In-Fusion assembly: seamless engineering of multidomain fusion proteins, modular vectors, and mutations," BioTechniques, vol. 43, no. 3, pp. 354-359, 2007.

[36] S. Auxilien, F. El Khadali, A. Rasmussen, S. Douthwaite, and H. Grosjean, "Archease from Pyrococcus abyssi improves substrate specificity and solubility of a tRNA $\mathrm{m}^{5} \mathrm{C}$ methyltransferase," Journal of Biological Chemistry, vol. 282, no. 26, pp. 1871118721, 2007.

[37] R. Gupta, "Halobacterium volcanii tRNAs. Identification of 41 tRNAs covering all amino acids, and the sequences of 33 class I tRNAs," Journal of Biological Chemistry, vol. 259, no. 15, pp. 9461-9471, 1984.

[38] R. M. McCarty, Á. Somogyi, G. Lin, N. E. Jacobsen, and V. Bandarian, "The deazapurine biosynthetic pathway revealed: in vitro enzymatic synthesis of PreQ $Q_{0}$ from guanosine $5^{\prime}$ triphosphate in four steps," Biochemistry, vol. 48, no. 18, pp. 3847-3852, 2009.

[39] J. S. Reader, D. Metzgar, P. Schimmel, and V. De CrécyLagard, "Identification of four genes necessary for biosynthesis of the modified nucleoside queuosine," Journal of Biological Chemistry, vol. 279, no. 8, pp. 6280-6285, 2004.

[40] M. Watanabe, M. Matsuo, S. Tanaka et al., "Biosynthesis of archaeosine, a novel derivative of 7-deazaguanosine specific to archaeal tRNA, proceeds via a pathway involving base replacement on the tRNA polynucleotide chain," Journal of Biological Chemistry, vol. 272, no. 32, pp. 20146-20151, 1997.

[41] M. Sprinzl, C. Steegborn, F. Hübel, and S. Steinberg, "Compilation of tRNA sequences and sequences of tRNA genes," Nucleic Acids Research, vol. 24, no. 1, pp. 68-72, 1996.

[42] N. Altman-Price and M. Mevarech, "Genetic evidence for the importance of protein acetylation and protein deacetylation in the halophilic archaeon Haloferax volcanii," Journal of Bacteriology, vol. 191, no. 5, pp. 1610-1617, 2009.

[43] E. Bab-Dinitz, H. Shmuely, J. Maupin-Furlow, J. Eichler, and B. Shaanan, "Haloferax volcanii PitA: an example of functional interaction between the Pfam chlorite dismutase and antibiotic biosynthesis monooxygenase families?" Bioinformatics, vol. 22, no. 6, pp. 671-675, 2006. 
[44] A. Large, C. Stamme, C. Lange et al., "Characterization of a tightly controlled promoter of the halophilic archaeon Haloferax volcanii and its use in the analysis of the essential cct1 gene," Molecular Microbiology, vol. 66, no. 5, pp. 10921106, 2007.

[45] T. Suzuki, Y. Ikeuchi, S. Kimura et al., "Agmatine-conjugated cytidine in a tRNA anticodon is essential for AUA decoding in archaea," Nature Chemical Biology, vol. 6, no. 4, pp. 277-282, 2010.

[46] D. Mandal, C. Köhrer, D. Su et al., "Agmatidine, a modified cytidine in the anticodon of archaeal tRNA(Ile), base pairs with adenosine but not with guanosine," Proceedings of the National Academy of Sciences of the United States of America, vol. 107, no. 7, pp. 2872-2877, 2010.

[47] A. Soma, Y. Ikeuchi, S. Kanemasa et al., "An RNA-modifying enzyme that governs both the codon and amino acid specificities of isoleucine tRNA," Molecular Cell, vol. 12, no. 3, pp. 689-698, 2003.

[48] B. El Yacoubi, B. Lyons, Y. Cruz et al., "The universal YrdC/Sua5 family is required for the formation of threonylcarbamoyladenosine in tRNA," Nucleic Acids Research, vol. 37, no. 9, pp. 2894-2909, 2009.

[49] A. Kaur, P. T. Van, C. R. Busch et al., "Coordination of frontline defense mechanisms under severe oxidative stress," Molecular Systems Biology, vol. 6, article no. 393, 2010.

[50] T. Baba, H.-C. Huan, K. Datsenko, B. L. Wanner, and H. Mori, "The applications of systematic in-frame, single-gene knockout mutant collection of Escherichia coli K-12," Methods in Molecular Biology, vol. 416, pp. 183-194, 2007.

[51] M. Durot, F. Le Fèvre, V. de Berardinis et al., "Iterative reconstruction of a global metabolic model of Acinetobacter baylyi ADP1 using high-throughput growth phenotype and gene essentiality data," BMC Systems Biology, vol. 2, article no. 85, 2008.

[52] L. Zhou, X.-H. Lei, B. R. Bochner, and B. L. Wanner, "Phenotype microArray analysis of Escherichia coli K-12 mutants with deletions of all two-component systems," Journal of Bacteriology, vol. 185, no. 16, pp. 4956-4972, 2003.

[53] B. R. Bochner, "Global phenotypic characterization of bacteria,” FEMS Microbiology Reviews, vol. 33, no. 1, pp. 191-205, 2009.

[54] T. C. Fleischer, C. M. Weaver, K. J. McAfee, J. L. Jennings, and A. J. Link, "Systematic identification and functional screens of uncharacterized proteins associated with eukaryotic ribosomal complexes," Genes and Development, vol. 20, no. 10, pp. 1294-1307, 2006.

[55] H. Grosjean, C. Gaspin, C. Marck, W. A. Decatur, and V. de Crécy-Lagard, "RNomics and Modomics in the halophilic archaea Haloferax volcanii: identification of RNA modification genes," BMC Genomics, vol. 9, article no. 470, 2008.

[56] M. G. Gomez-Lorenzo, C. M. T. Spahn, R. K. Agrawal et al., "Three-dimensional cryo-electron microscopy localization of EF2 in the Saccharomyces cerevisiae 80 S ribosome at $17.5 \AA$ resolution," EMBO Journal, vol. 19, no. 11, pp. 2710-2718, 2000.

[57] B. G. Van Ness, J. B. Howard, and J. W. Bodley, "ADPribosylation of elongation factor 2 by diphtheria toxin. Isolation and properties of the novel ribosyl-amino acid and its hydrolysis products," Journal of Biological Chemistry, vol. 255, no. 22, pp. 10717-10720, 1980.

[58] B. G. Van Ness, J. B. Howard, and J. W. Bodley, "ADPribosylation of elongation factor 2 by diphtheria toxin. NMR spectra and proposed structures of ribosyl-diphthamide and its hydrolysis products," Journal of Biological Chemistry, vol. 255, no. 22, pp. 10710-10716, 1980.

[59] P. A. Ortiz, R. Ulloque, G. K. Kihara, H. Zheng, and T. G. Kinzy, "Translation elongation factor 2 anticodon mimicry domain mutants affect fidelity and diphtheria toxin resistance," Journal of Biological Chemistry, vol. 281, no. 43, pp. 32639-32648, 2006.

[60] C.-M. Chen and R. R. Behringer, "Ovcal regulates cell proliferation, embryonic development, and tumorigenesis," Genes and Development, vol. 18, no. 3, pp. 320-332, 2004.

[61] T. R. Webb, S. H. Cross, L. McKie et al., "Diphthamide modification of eEF2 requires a J-domain protein and is essential for normal development," Journal of Cell Science, vol. 121, no. 19, pp. 3140-3145, 2008.

[62] B. S. Laursen, I. Siwanowicz, G. Larigauderie et al., "Characterization of mutations in the GTP-binding domain of IF2 resulting in cold-sensitive growth of Escherichia coli," Journal of Molecular Biology, vol. 326, no. 2, pp. 543-551, 2003.

[63] Z. Zhou and M. P. Deutscher, "An essential function for the phosphate-dependent exoribonucleases RNase $\mathrm{PH}$ and polynucleotide phosphorylase," Journal of Bacteriology, vol. 179, no. 13, pp. 4391-4395, 1997.

[64] Y. Zhang, X. Zhu, A. T. Torelli et al., "Diphthamide biosynthesis requires an organic radical generated by an iron-sulphur enzyme," Nature, vol. 465, no. 7300, pp. 891-896, 2010.

[65] L. Jovine, S. Djordjevic, and D. Rhodes, "The crystal structure of yeast phenylalanine tRNA at $2.0 \AA$ resolution: cleavage by $\mathrm{Mg}^{2+}$ in 15-year old crystals," Journal of Molecular Biology, vol. 301, no. 2, pp. 401-414, 2000.

[66] H. Shi and P. B. Moore, "The crystal structure of yeast phenylalanine tRNA at $1.93 \AA$ resolution: a classic structure revisited," RNA, vol. 6, no. 8, pp. 1091-1105, 2000.

[67] R. Oliva, A. Tramontano, and L. Cavallo, " $\mathrm{Mg}^{2+}$ binding and archaeosine modification stabilize the G15-C48 Levitt base pair in tRNAs," RNA, vol. 13, no. 9, pp. 1427-1436, 2007. 

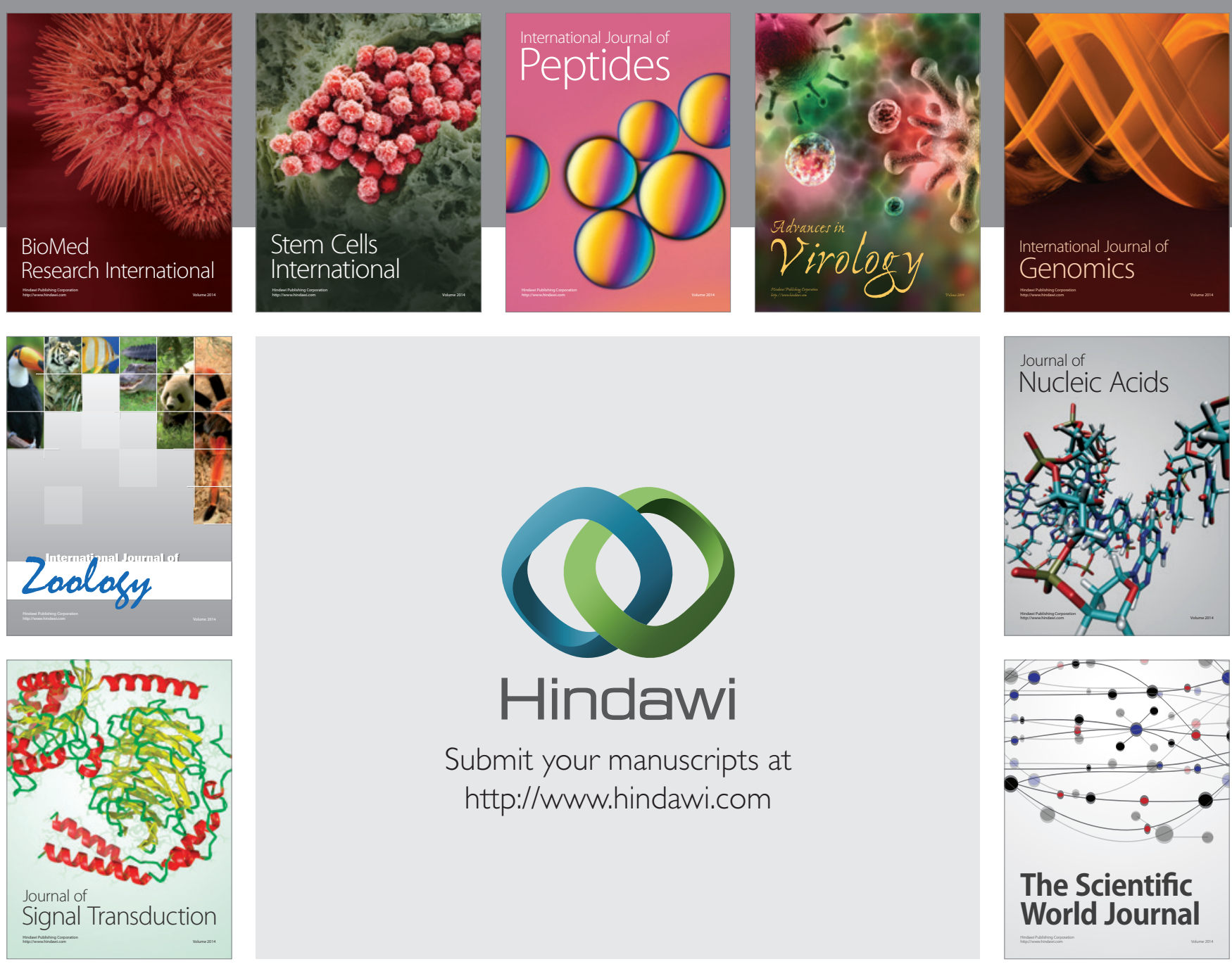

Submit your manuscripts at

http://www.hindawi.com
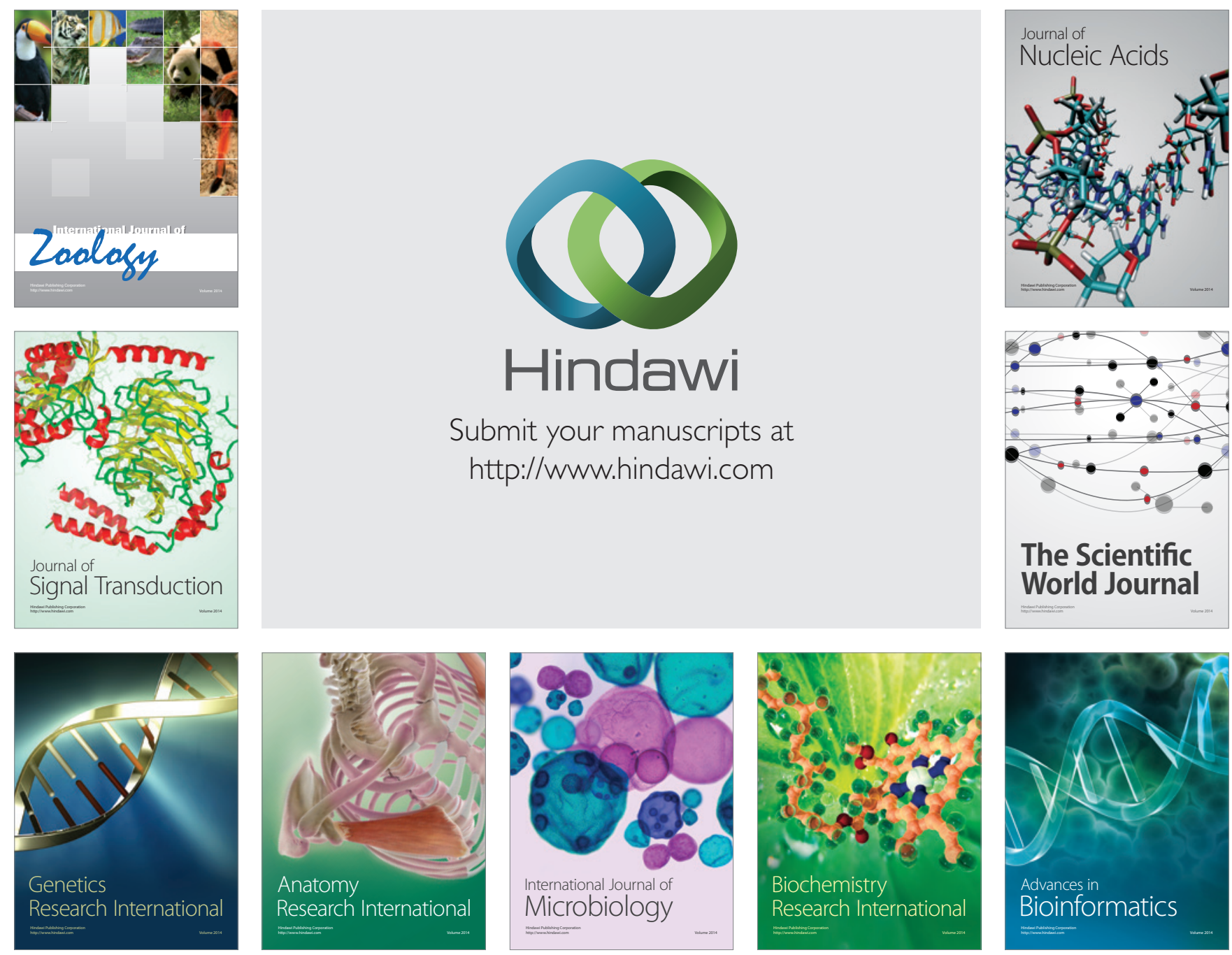

The Scientific World Journal
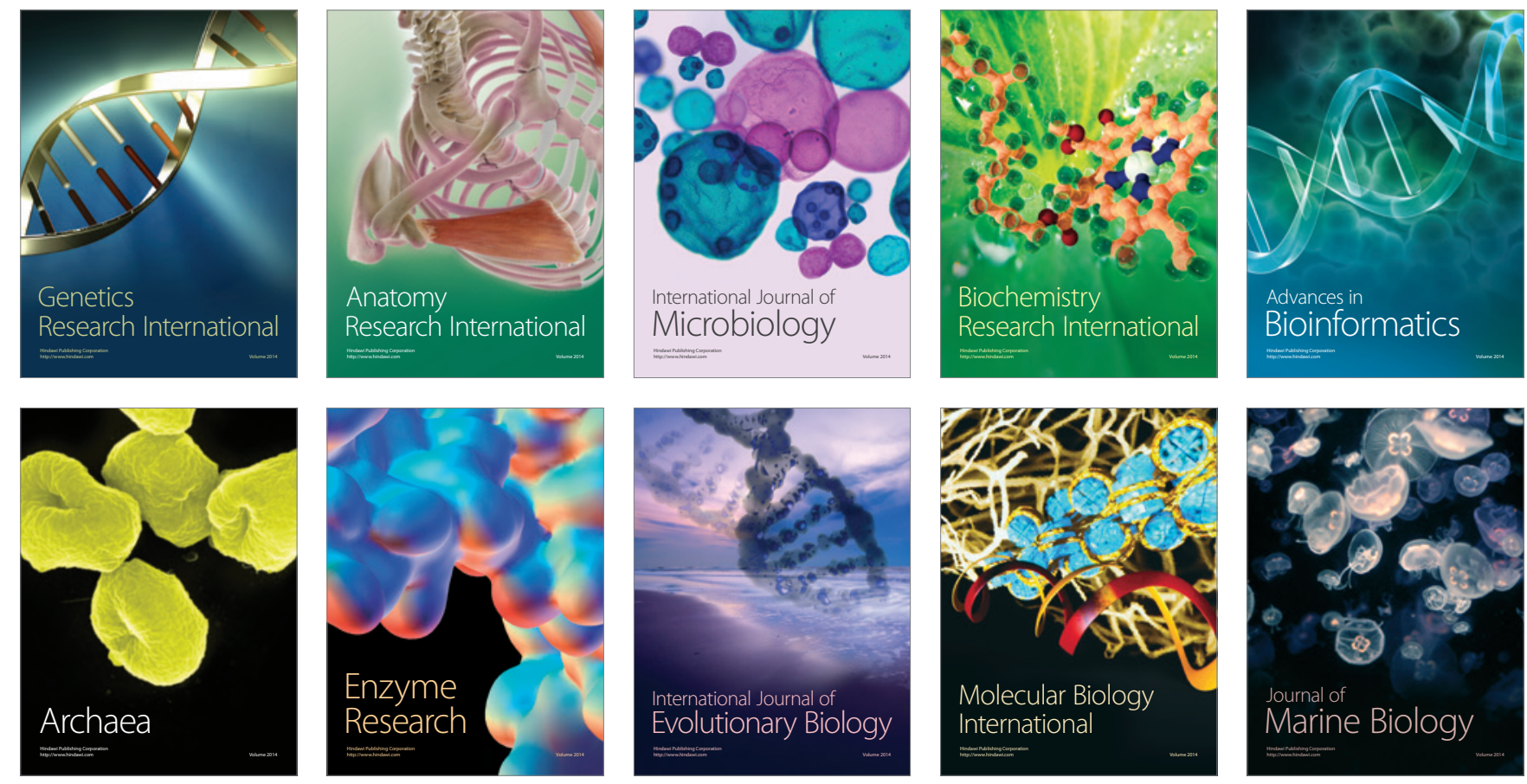